\title{
WorkingPlaces, Furniture and Technology: Strategies of Flexibility of University Library Buildings - the Case of Bozen/Bolzano
}

by KLAUS KEMPF

The slides of this paper can be found at: http://www.zhbluzern.ch/LIBER-

LAG/PP_LAG_04/Wednesday/K_Kempf/LIBERBozen04-korr.pdf

\section{"FLEXIBILITY" AS THE BASIC PRINCIPLE OF MODERN LIBRARY BUILDINGS}

For centuries people have visited libraries to find information, and the practical needs of housing collections and accommodating readers have been the driving force behind library design. As technology advances of the past 20 years have made it possible for people to find information without entering a library building, some have even asked whether the bricks-and-mortar library is doomed to extinction. But today we know that this (bad) vision hasn't come true. Of course, it was imperative to rethink library services fundamentally and in this context also to rethink completely the functions of library buildings. In this ongoing process one term became more and more a magic word - "flexibility"!

When Gerhard Liebers, the doyen of building libraries in Germany, came back from a study tour to the United States in the early fifties, his experiences condensed in the term "flexibility". He was absolutely enchanted by the in those days modern and in Germany, at least in the field of library construction, still unknown modular construction principle (Liebers, 2002). Over the years the requirement of flexibility as an important aspect in the planning and briefing of new library buildings became more and more important. Today it is regarded as one of the most decisive, perhaps the basic principle of modern library buildings and in particular it got a new quality.

\section{"FLEXIBILITY" IN HYBRID LIBRARY TIMES}

At the moment libraries live through a period of transition and radical change. They have to deal with printed as well as digital materials, both of which with specific requirements in terms of the library building design. The library concept is changing to a so-called "hybrid library". However, this means more than the housing of a variety of different materials under one roof and the development of a new service concept. The advent of the networked digital world has not led to the "deserted library", abandoned by students and users, as had always been feared (Carlson, 2001). The opposite took place: We experience today the revival of the library as a place of learning and study (Engel \& Antell, 2004).

The hybrid library asks for the following qualities:

- $\quad$ Learners have different preferences: different learning styles mean a need for study space varieties and "zoning", such as quiet private areas, and busy social areas with low-level seating and tables, and with refreshment facilities.

- $\quad$ Learning is more collaborative: a need for "collaboratories", such as group study tables and rooms with shared access to technology and presentation facilities.

- Technology is developing rapidly: a need for facilities for continual training and retraining of users in large classes, small groups and as individuals.

- $\quad$ Access to network resources is universal: a need for cable management for wired-up study places - both computer workstations and plug-in points for laptops (Corral \& Brewerton, 1999). 


\section{HYBRID LIBRARY FEATURES}

It is assumed that learning will become more collaborative, learners have different preferences, technology will continue and network access to information will be imperative. Thus, in addition to providing ready access to large book and periodical collections, hybrid library features will include:

- group study areas, whether separate rooms or zoned, with ICT capabilities;

- $\quad$ varied, and zoned, study accommodation, and social space;

- $\quad$ training facilities and help desks to demonstrate systems, services and techniques;

- $\quad$ computer workstations and wired up reader places as well as in the case of the existing of a wireless LAN lap top dock-in facilities.

The design features that symbolise the libraries changing role from custodian to gateway, and which effectively bring together users and resources are:

- $\quad$ as few as permanent internal walls as possible,

- $\quad$ systematic zoning of areas for different activities,

- $\quad$ an extensive and accessible network and power grid to enable the connection of reader places,

- $\quad$ load bearing floors sufficient for book stacks throughout the building.

This leads us to the remarks of Faulkner Brown (Faulkner Brown, 1989) and Andrew McDonald (McDonald, 1997) that "flexibility or adaptability of space is a key criterion". Thus the modern, student-friendly university library is focused on the following qualities:

- flexibility: the ability to reconfigure layout to match users changing requirements,

- $\quad$ variety: the provision of a "family" of spaces that facilitate different forms of learning (Powell, 2002).

\section{THE LEARNING CENTRE IDEA}

The new idea of a "hybrid library building" quickly turned into reality. The birthplace of the first representatives of this new generation of library buildings was Great Britain. There, in the first half of the 90s in Great Britain in consequence of the so-called Follett Report (1993), which was the result of a research study about the future of universities and university libraries in the UK, was born a new concept of a university library. The absolute necessity to save money led to the conviction that the bundling of learning resources and a more student centred university management could offer a way out of the deep financial crisis of the British universities. Students who pay for their study were considered as customers who should find all they need "under one roof". At the same time this could be a low budget solution. That was the right moment to shape a new idea of university libraries and for the establishment of so-called "Learning centres" or "Learning resource centres". One of the protagonists of this idea was G. Bulpitt and his project, the Adsett Center of the Hallam University of Sheffield which is one of the most outstanding examples (Bulpitt, 1999).

One important attribute of this new concept of a scholarly library and the library building is the respect for different "learning styles" and how they dynamically change from more independent to more group-based varieties and vice versa. Scott Bennett retains even that the "comeback" of the libraries could be eased by supporting collaborative learning by offering adequate learning facilities (Bennett, 2003). 
The motto of the Free University of Bozen is: small, but beautiful - focused on teaching and learning and internationally minded. The library is considered an integrated part of the university concept and recognized as "the heart of the university".

The library concept lives up to the principles of the university concept:

- (multimedia) information centre of the university and the region,

- innovative and internationally minded,

- $\quad$ a place to study and to learn

I'll try to verify whether and how the Bozen building lives up to the above-mentioned requirements of flexibility of a library building in times of the "hybrid library". But first of all let us take a look on the main characteristics of the new construction.

\section{Main characteristics and particularities of the new library facility}

The creation of new spaces for the university library was part of the project to erect a completely new university site close to the historical centre of Bozen; therefore in the year 1998 a Europe-wide architecture competition was organized. The winner project provided the library facilities in the central building of the new campus.

This building is a "public building" in the literal meaning of the term - open to the university and open to the town. It forms a monumental portal between the town and the university. It is a rather introverted construction. In the architect brief it was required, taking into consideration the micro climate in Bozen, in summer one of the hottest towns in Italy, not to create a "greenhouse", i.e. no light-flooded constructions of glass and steel which we often find today in Central and Northern European countries. The philosophy of the design of the winning project respects this intention very well. The building forms a very closed and hermetic looking space, only interrupted by a line of windows on the east side of the facade. From the architects' point-of-view, it is supposed to resemble an ancient Roman house - from the outside very modest, even rejecting, inside offering a lot of open space around the atrium or more precisely around a central light well.

In the same building, on the ground floor are accommodated the student restaurant and the cafeteria; besides the entrance to the library - on the first floor - are located the student administration offices. Beneath the roof of the building the students can find the facilities of the computer and the language centre.

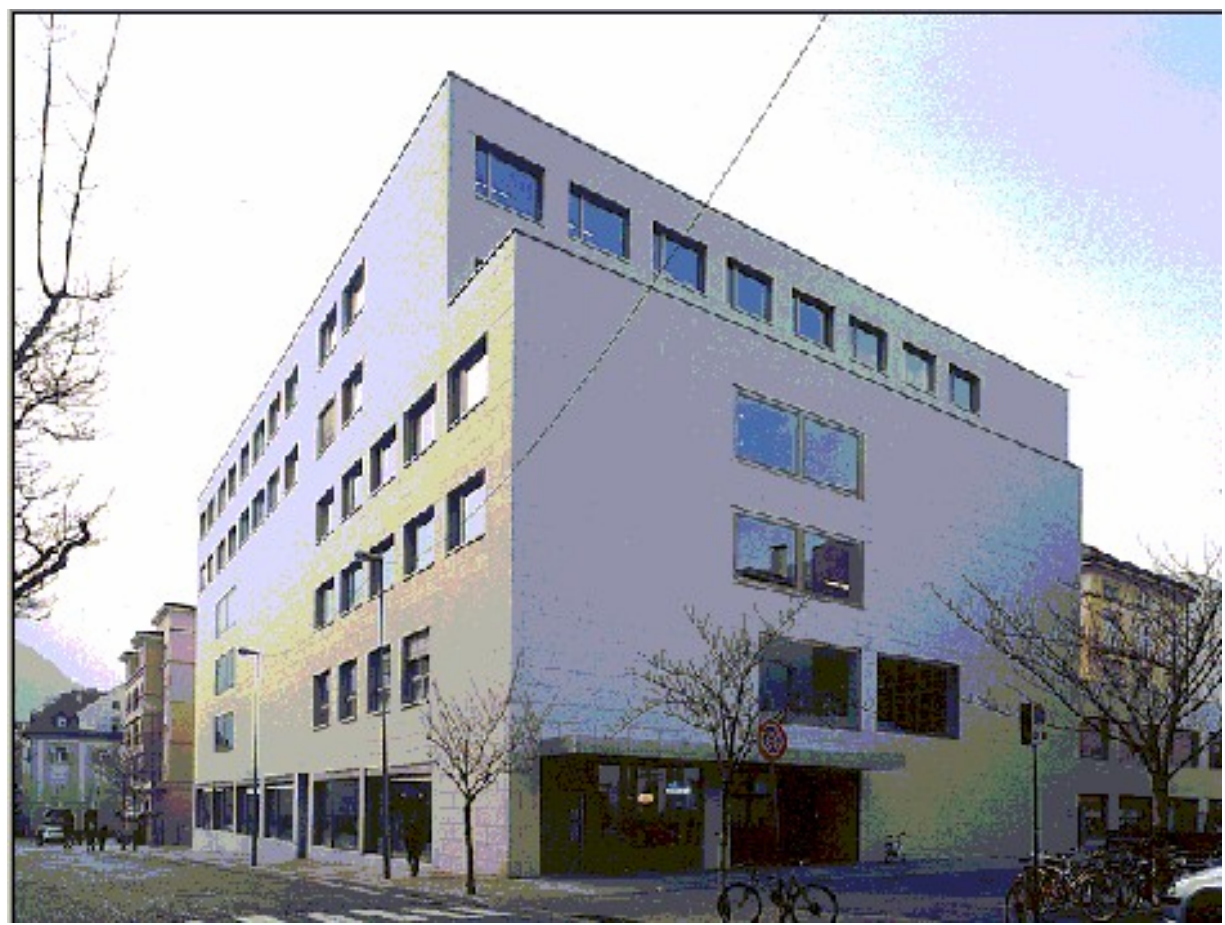

So the library is really situated at the crossing of all the central services and "under one roof" the student can do all the activities - with exception of attending lectures - which are particularly important for his daily life at the university. The library space itself (in the part accessible for the user) consists of a 4-storey facility which extends from the first floor up to the 4th floor of the building around a central light well; in the first basement, under the student restaurant is accommodated and not accessible for the user the (compact shelved) stacks. 


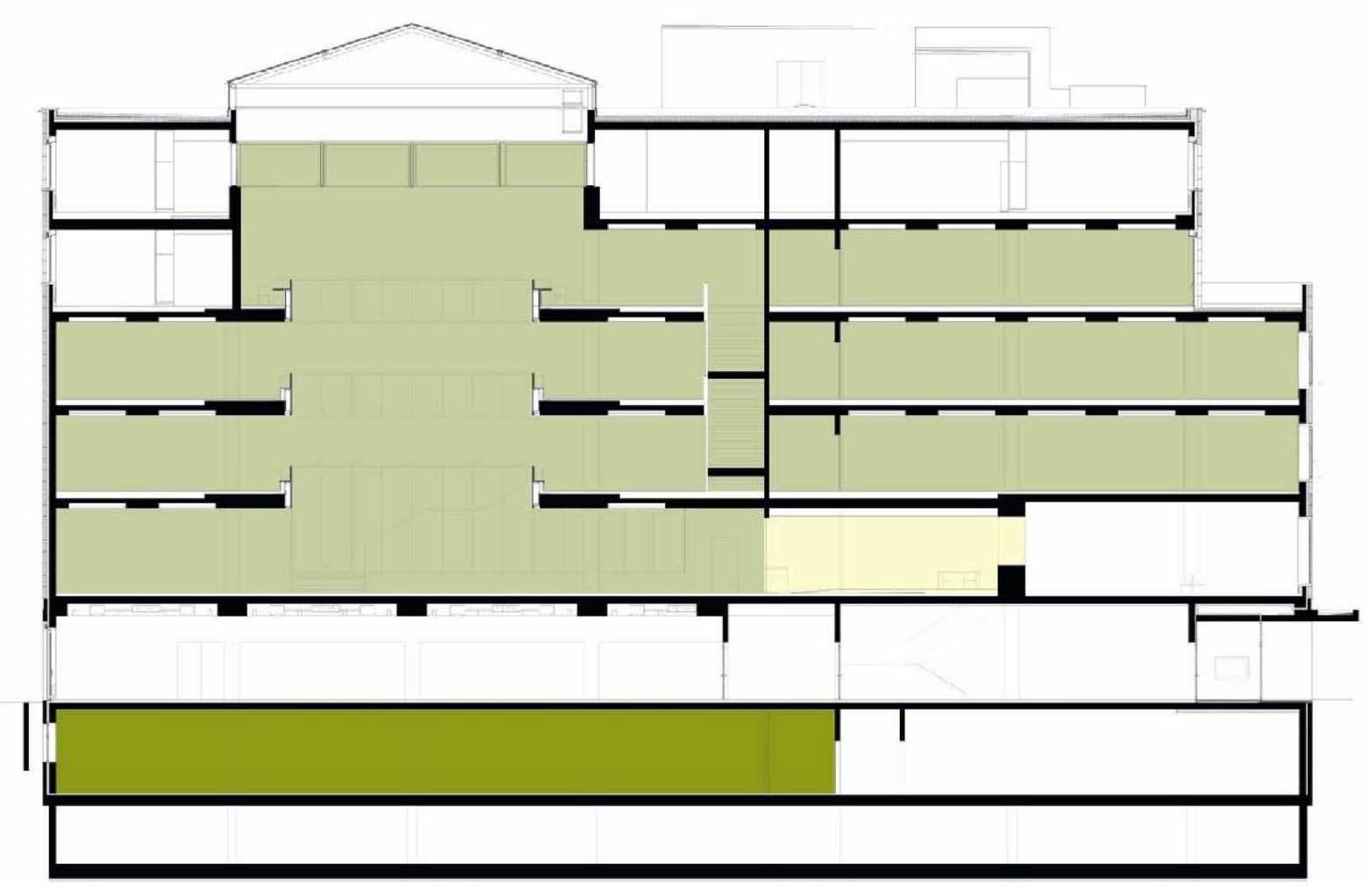

The library facilities are very spacious: The overall usable space amounts to $5.156 \mathrm{~m}^{2}$, of which $3.254 \mathrm{~m}^{2}$ are open access shelving (for at least 300.000 volumes) and reader places area (of which $865 \mathrm{~m}^{2}$ are lockable); the staff or office area (including the very spacious issuing and inquiry desk area) covers $317 \mathrm{~m}^{2}$ and the closed stacks area comprises $720 \mathrm{~m}^{2}$, enough to house 100.000 books as it was required in the architecture brief.

Let us take a short walk around the library: Starting on the ground floor where the main part of the space is occupied by the student restaurant and the cafeteria, which is also open to the public. Via a not very inviting staircase - this is definitively not a good solution to bring people into the library - we arrive on the first floor. Turning to the right hand side in a very large corridor and just in front of the entrance of the library we meet a very spacious and relaxing newspaper lounge; passing the exhibition and/or conference room we arrive at the (controlled) entrance to the library facilities with the central information/inquiry/issuing desk on the right hand side and the cloakroom on the left hand side. The first floor or better the "ground floor" of the library facility houses also in a very compact way a cluster of staff offices.

In the midst of the building, the second and the third floor are structured in an identical way:

- On both levels, alternating with clusters of book stacks, we always find close to the windows 3 "islands" of user workplaces;

- On each of the two floors in the east corner of the building is located a cluster of carrels/small group study rooms and

- $\quad$ in the west corner of the building - on each of the two floors - a cluster of 4 very spacious seminar rooms

On the fourth level of the building around the library spaces are the facilities of the computer and the language centre. Also here in an alternating way we have the mixture of lockable spaces (a cluster of carrels) and the open access shelving and reader place area. Here is the "Silentium area" of the library with a lot of reader places primarily for the use of print material (and, if not noisy, laptops). Another attraction for users here on the top floor of the library facility is the opportunity to enjoy - thanks to a large and sunny balcony - open-air atmosphere.

\section{Variety of different workplaces}

First of all is to underline an extremely high number of user workplaces. The library offers altogether 520 user workplaces; considering the number of students at the Bozen Campus - at the moment a little bit more than 1000 - the ratio between the number of potential users and the workplaces available is extremely favourable. The recommendation in Germany for library facilities in the Social sciences and Humanities provides a ratio of 1 (workplace) : 12 - 15 (potential users/registered students). In Bozen the situation is radically different. It sounds like a fairy tale: the ratio is $1: 2$ ! 
Also the criterion, variety of different workplaces, lives up extraordinarily well to the general requirements given at the beginning of the statement. There is a real "family" of very different work- and reader places, supporting any learning and study style. There are:

- $\quad$ Reader places in the so-called newspaper lounge (in front of the library entrance) with the possibility of quick information and/or a relaxed break on easy seats.

- $\quad$ A cluster of computer-based workplaces in the "information area" close to the library entrance primarily dedicated to OPAC- and/or database researches and assisted by the staff in face-to-face-support.

- $\quad$ Not a user workplace in the strict meaning of the term, just to make browsing between the stacks and the shelved books more comfortable and to allow a quick look into the book, but an imperative in a fashionably furnished modern library building: the "pull-out reference shelf"

- $\quad$ The librarians were very sceptical, but even reader places which are very closely situated to the noise transmitting central light well, type bench, on the $2^{\text {nd }}$ and $3^{\text {rd }}$ floor are accepted and used as "intermediate sit-down-and reading-arrangements" by the patrons

- A chain of workplaces on one long table which is winding like a crown around the balustrade of the central light well on the $4^{\text {th }}$ floor; every workplace is equipped with a desk lamp which can be switched on and off individually.

- $\quad$ Workplaces (with laptop docking possibility and equipped with individual desk lamps) zoned as "work place islands" between the bookstacks in the open access area on the $2^{\text {nd }}$ and $3^{\text {rd }}$ floor.

- $\quad$ A variety of lockable workplaces: the $2^{\text {nd }}$ and $3^{\text {rd }}$ level of the building are structured, as just mentioned, in an identical way. Here we have a mixture of open access areas and lockable spaces. More than $800 \mathrm{~m}^{2}$ of the overall existing usable space of the building used for library purposes is lockable. Lockable space means a more individual use of space, in particular it allows, even promotes "team work" amongst the students. To create as much group based working facilities as possible was also one of the key requirements in the architect brief. The main part of these rooms has windows and they have quite good daylight.

The lockable spaces are arranged as clusters. There are three categories of lockable spaces:

- $\quad$ One and more person carrels (so-called "studies"): the best privacy and the most intimate atmosphere are guaranteed by the carrels or studies. The surface of a single carrel amounts to $9-11 \mathrm{~m}^{2}$, which is rather spacious and without problems it could host also a little working group of 2, 3 or even 4 students. The surface of a twoperson-cabin amounts to $11-13 \mathrm{~m}^{2}$. The equipment standard comprises: table (docking possibility to the LAN); seat and bookshelf. As one can imagine, the carrels are heavily used.

- $\quad$ Small group study rooms: each surface amounts to approximately $31 \mathrm{~m}^{2}$; equipped with tables (providing docking to the LAN), seats and a large book stack.

- Seminar or so-called large group study rooms: facilities with or without computer based workplaces; each of them comprises approximately $50 \mathrm{~m}^{2}$. They are well equipped with filing cabinets, rolling seats, tables and presentation facilities. The facilities are not only used by students in the way of self-organized study group work, but also for user instruction (done by the library staff) and as lecture halls (by the faculty).

\section{LIGHTING AND ACOUSTICS IN THE "HYBRID LIBRARY"}

Lighting and acoustics are considered as some of the crucial points and often even as the major problems in modern library buildings, type student-centred library. The development of open-space libraries in general has increasingly led to noise problems, especially as it seems to coincide with the tendency for students to work in (often chatty) groups. Some users complain that group work noise undermines private study. However, we have to take into consideration that the phenomenon "acoustics-noise" is a very subjective feeling. Some readers even like an "active" or noisy social learning environment, whereas others have a preference for quiet study places with good acoustics and visual privacy.

The lighting problem is a double one. The problem is no longer to guarantee the user an optimal daylight reader place and to protect the deposited material as much as possible against paper destroying sunlight. Rather the problem of today is to develop an adequate lighting scheme, which satisfies the needs of the simple book reader who prefers a daylight workplace, and at the same time is computer- or rather screen-friendly and supports and promotes the use of computers in the library. 
The library building of Bozen has a complicating lighting as well as acoustic situation. It is intended that the variety of space will allow students to find optimum working conditions on each visit: the type of study places which suits them, the right level of noise, and the appropriate lighting

\section{Lighting situation in the Bozen building}

The design of the Bozen university library tries to provide lighting, which meets both readers' needs and computer/screen requirements. The limited number of windows leads to the channelling and/or filtering of the daylight to certain parts of the building only. The latter is helpful for the zoning of the workplaces (classical reader places close to the windows, computer based work places put more distantly in the darker parts of the building). The central light well, covered by a glass roof, allows only the entry of filtered daylight. Only immediately beneath the glassed roof of the light well (on the $4^{\text {th }}$ floor) there is plenty of sunlight and on the same floor the long balcony window front guarantees "sun bathed" reader places; on the $2^{\text {nd }}$ and on the $3^{\text {rd }}$ floor reader places situated immediately at the "well border" also get enough light. The rest of the library space is dived in a scattered light. Although this form of lighting is really screen friendly most of the users and in particular the staff prefer in addition also during the day hours a permanently switched on artificial (down-)light.

\section{Anti-noise strategy used in the Bozen building}

The concept of the library - in particular as student centred facility and the special characteristics of the design of the university library - force to think about an adequate anti-noise strategy. Primary noise sources in the library facility are the central staircase, at least the part connecting the $1^{\text {st }}$ and the $2^{\text {nd }}$ floor and the floor crossing central light well which works as a enormous "noise transmitter". While the problem of the staircase can be resolved only by radical intervention, it is erected badly and needs a complete reconstruction; the central light well is a basic element of the design concept and therefore cannot be eliminated.

In the struggle against noise we make use of "classical" remedies - to put a sound absorbing carpet on the floor and/or the use of noise absorbent surface materials under the ceiling and/or along the walls. But in open-plan buildings this normally isn't enough. In constructions like the Bozen library facility with its very open structure and the four storeys crossing central light noise cannot be extinguished only by a traditional anti-noise strategy.

Very helpful in the struggle with undesired noise is a sufficient depth of space on each floor. The further away from the noise sources, here the central light well, a workplace is situated, the quieter the workplace. In the case of Bozen the depth of space on the $2^{\text {nd }}$ and $3^{\text {rd }}$ floor is sufficient to put work places at a minimum of $10 \mathrm{~m}$ and more than $30 \mathrm{~m}$ away from the central light well, which are relatively quiet and in the second case even silent; on the $4^{\text {th }}$ floor the socalled "Silentium area" is more than 30m away from the light well balustrade.

A corrective can be also a consequent zoning - different user activities have been designated separate zones; zones delineates and physically separates various activities, notably the division between PC areas, quiet study areas and group study areas, and their respective acceptable levels of noise. Each zone accommodates different study space. The PC areas, for example, provide open-plan workstations where informal group work is permitted. By contrast, the quiet study areas, composed also of carrels, are essentially quiet reading areas for students using printed material and/or laptops. The principle should be that quiet study areas should be situated away from noisy high traffic and group study areas.

This policy was adopted in Bozen: to create a positive acoustic situation in the whole building led to the decision to locate acoustically problematic activities (and services) on the $1^{\text {st }}$ floor, close to the entrance. Consequently, levels become quieter as one moves up the building; the top floor even has been set aside for quiet study and is called "Silentium area". On the various levels the block of book stacks act as a "sound barrier", absorbing noise. The highest level of noise protection offer the soundproof (individually used) carrels. But there is a problem: the dividing walls between carrels and the neighbouring so-called small group study rooms aren't soundproof, it's a simple (closed) wooden book stack construction.

\section{FLEXIBILITY IN TECHNOLOGY - THE LOCAL AREA NETWORK (LAN)}

A frequently expressed design objective is to wire-up as much space as affordable with network and power ports to maximise the building's convertibility but also, in part, to allow laptop computer use, although associated keyboard noise and need for sound proofing in quiet study areas is an important concern. Bazillon emphasises the need to accommodate the use of computers (including laptops) with network access built into study spaces. "Study spaces thus become self-contained work areas in which research and writing may be done with relative ease." (Bazillion \& Braun, 1995). 
The situation in Bozen is as follows:

- Only 48 networked and computer-based IT workstations are available (in lockable and open spaces), because the students find a considerable number of open accessible workstations in the faculties rooms and/or the computer centre facilities.

- $\quad$ Laptop plug-in or drop-in points are spread over the whole library facility.

- From all the 520 reader places (computer based or not) access to the (wired) LAN exists.

- The cavity floor permits a completely flexible cabling/wiring in the whole building.

- $\quad$ Since February 2004 also the "wireless" LAN is accessible in the library, but the wired LAN is still working, because it is much faster and has a higher security standard.

- $\quad$ The advantage of the wireless LAN - more economic (for the university) and more comfortable (for the students), because a plug-in to the LAN is also possible in areas where there is no cable (for instance, in the student restaurant and the cafeteria)

\section{FLEXIBILITY IN FURNISHING}

Furnishing forms an integrated part of any library building concept. There is often a controversial debate between architects and librarians about the various aspects of furnishing. But a compromise should be found. The general motto: "The more functional and the more flexible the better for librarians and the users" can also be applied here. The aspect of flexibility in furnishing means in particular the usage of standardized products, which allow the library an ease change or extension. Especially designed furniture, in particular book stacks and work place furniture should be the absolute exception and in general avoided. In the case of Bozen this "golden principle" was taken in consideration for the choice of the book stacks as well as for the work place furniture:

Book stacks: in principle all spaces in the building can be used for all library purposes. The load capacity of the (cavity) floor construction is sufficient to put the book stacks (even compact stacks) in any part of the open access area. The installed book stacks (in the open access area) are standard products and can be handled easily. Only in and outside of the carrels and/or small group study rooms are (wooden) book stack constructions made by a cabinetmaker and not so easy to move.

Work place furniture (in the user and staff areas): seats and desks are standardized products. They can be rearranged and/or changed without problems.

\section{CONCLUSION}

In life dreams rarely come true, and even less so in library building. In the construction and design of the university library of Bozen it was attempted to transform into reality as much as possible of the conceptual ideas i.e. the servicecentred library, which had inspired the foundation and organisation of the new library from the very beginning. Given a first draft, which only partly reflected the librarians' wishes, eventually a compromise acceptable to both sides was reached after an intensive dialogue with the architects. The result is quite remarkable, especially as regards the library as a place of learning. The library rooms are very well accepted by its users, in particular the students. Or to put it in a nutshell: not a perfect world, but a highly functional and convenient learning environment.

\section{REFERENCES}

Bazillion, R.J. and C. Braun: Academic libraries as high tech gateways: a guide to design and space decisions. Chicago [u.a.] : American Library Association, 1995, p. 44

Bennet, S.: Libraries designed for learning. Washington, 2003. Pp. 16-19. 
Bulpitt, G.: "The Adsetts Learning Center, Sheffield Hallam University". In: Intelligent Library Buildings.

Proceedings of the $10^{\text {th }}$ Seminar of the IFLA Section on Library Buildings and Equipment. The Hague, Netherlands, 24-29 August 1997. München : Saur, 1999, Pp.. 245-259.

Carlson, Scott: "The Deserted Library: As Students Work Online, Reading Rooms Empty Out, Leading Some Campuses to Add Starbucks". Chronicle of Higher Education, (November 16, 2001).

http://chronicle.com/free/v48/i12/12a03501.htm

Corral, S. and A. Brewerton: The new professional's handbook: your guide to information services management. London : Library Association, 1999, p. 214.

Engel, D. and K. Antell: "The life of the mind: A study of faculty spaces in academic libraries". College \& Research Libraries, 65(2004)1, pp. 9-11.

Faulkner Brown, H.: "The open plan and flexibility". In: International Association of Technological University Libraries, Proceedings 11. London : IATUL, 1989, pp. 3-9.

The Follett Report. Bristol : Joint Funding Council's Libraries Review Group, 1993. http://www.ukoln.ac.uk/services/papers/follett/report/

Liebers, Gerhard: "Der Gedanke der 'flexibility' im neueren amerikanischen Bibliotheksbau". In: Liebers, Gerhard: Funktion und Gestalt der Bibliothek. Frankfurt an Mainz [u.a.] : Lang, 2002, 2., korrigierte Aufl., S. 9-26.

McDonald, A.: "Space planning and management". In: Baker, D.,ed.: Resource management in academic libraries. London : Library Association, 1997, pp. 189-206.

Powell, M.: "Designing library space to facilitate learning: A review of the UK higher education sector". Libri, 52(2002), p. 18 